\title{
Insulin, glucose and beta-hydroxybutyrate responses to a medium-chain triglyceride-based sports supplement: A pilot study
}

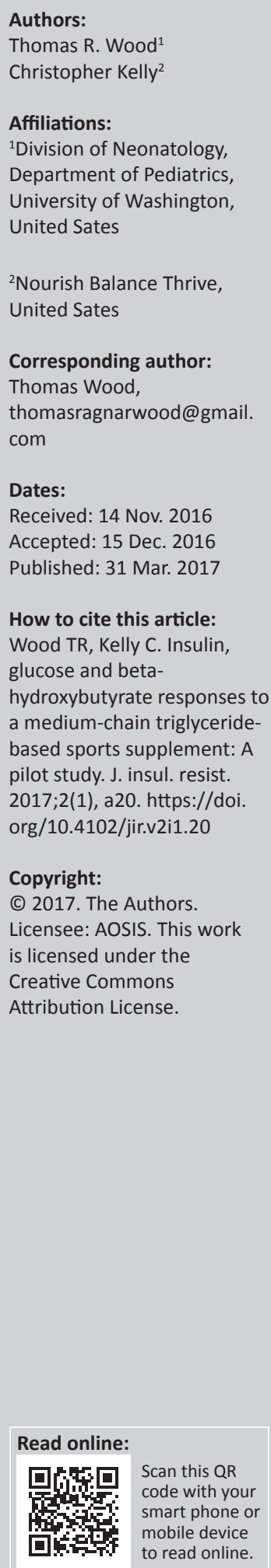

\begin{abstract}
There is a current trend in endurance sports to move athletes towards a low-carbohydrate diet or use periods of low carbohydrate consumption to increase both health and performance. As a result, a market is developing for sports supplements to provide nutritional support during training and racing for athletes who follow a low-carbohydrate lifestyle. PHAT FIBRE (PF) is a powdered sports supplement that includes medium-chain triglycerides suspended in a digestion-resistant carbohydrate and is tailored to the needs of low-carb athletes. Eleven healthy participants were administered $25 \mathrm{~g}$ of PF after an overnight fast. After 30 minutes, median blood glucose increased by $6 \mathrm{mg} / \mathrm{dl}$ from $94 \mathrm{mg} / \mathrm{dl}$ to $100 \mathrm{mg} / \mathrm{dl}(p=0.002)$. At the same time points, median blood beta-hydroxybutyrate (BHB) increased from $0.3 \mathrm{mmol} / \mathrm{L}$ to $0.5 \mathrm{mmol} / \mathrm{L}$. The increase in BHB was significant ( $p=0.02)$ after excluding one outlier who had elevated levels of fasting BHB. Insulin levels did not change significantly at any point during the study. In a single participant, a revised formulation of PF (PFv2) produced a $0.6 \mathrm{mmol} / \mathrm{L}$ increase in BHB with no effect on blood glucose. These data suggest that PF can provide a source of energy for the low-carb athlete by supporting ketone production without negatively impacting insulin or blood glucose levels.
\end{abstract}

\section{Introduction}

Over the last decade, there has been a large-scale re-examination, in both the popular and scientific literatures, about how to best fuel the human body. ${ }^{1,2}$ As a result, low-carbohydrate diets and nutritional ketosis are becoming increasingly considered for the treatment of chronic metabolic diseases such as obesity and the metabolic syndrome, as well as neurological diseases such as Alzheimer's disease and multiple sclerosis. ${ }^{3,4,5,6}$ The 'low-carb' paradigm has also translated to the fuelling of athletes during endurance exercise. Periods of cyclical low-carbohydrate intake during training can improve time trial performance in triathletes, ${ }^{7}$ and recent data have shown that 'ketoadapted' athletes have a dramatically increased ability to metabolise fat aerobically at higher percentages of VO2Max intensities. ${ }^{8}$

The fat-adapted athlete is able to rely on body adipose tissue, including intramuscular triglycerides, to provide fatty acids for aerobic metabolism for longer periods and at higher exercise intensities. ${ }^{8}$ However, there is increasing interest in supplements specific to the 'lowcarb' (endurance) athlete to support optimal energy metabolism during training or racing. To be most effective, these supplements should provide calories without significantly affecting blood glucose or insulin levels in a way that would inhibit endogenous lipolysis and reduce the capacity for beta-oxidation. One option is to provide a low glycaemic index carbohydrate source that produces smaller insulin and glucose responses compared to traditional sports fuels such as maltodextrin, but can still support the maintenance of glycogen levels during exercise. ${ }^{9}$ Supplemental fatty acids are also of particular interest to the low-carb athlete, especially medium-chain triglycerides (MCTs) (6-10 carbon saturated fatty acids). MCTs are metabolically unique due to their direct absorption into the portal circulation and subsequent ketogenesis in the liver. ${ }^{10}$ Ketone bodies increase cardiac efficiency and can be directly used by the skeletal muscle as an energy source during aerobic exercise. ${ }^{11,12}$ Exogenous ketone supplementation has also been shown to increase endurance cycling performance. ${ }^{13}$ Supplementing with MCTs results in dose-dependent increases in circulating ketone levels (usually measured as beta-hydroxybutyrate, or BHB), but may cause gastrointestinal (GI) distress in larger doses. ${ }^{3}$ 
Anecdotally, the GI effects of MCTs can be reduced when they are provided as a powder. However, most commercially available MCT-based powders include high glycaemic index carbohydrates (i.e. maltodextrin or highly branched cyclic dextrin), ${ }^{9,14}$ emulsifiers or caseinate salts. All of these have potential downsides: (1) high glycaemic index carbohydrates may increase the insulin response and suppress endogenous lipolysis, ${ }^{15}$ (2) emulsifiers can negatively affect GI health ${ }^{16,17,18}$ and (3) dairy constituents such as casein are common food allergens. ${ }^{19}$

Here, we report on an open-label pilot trial examining the glucose, insulin and BHB responses to an MCT-based sports supplement powder using a digestion-resistant carbohydrate as the sole powder component. The goal is to develop a powdered MCT source that overcomes the potential downsides of products currently available on the market.

\section{Methods}

\section{Study participants}

Healthy participants ( $n=11$; two women, nine men) were recruited via email and social media. Full demographic data are listed in Table 1. Four of the participants (three men, 1 women) were elite-level or professional athletes. Median (range) age was 40 (24-46) years. All of the participants had previous experience with a low-carbohydrate diet or with supplements that can boost blood ketone production (MCT oil or exogenous ketones). None of the participants had a history of disease that would interfere with metabolic responses to a calorie load. All participants performed their own measurements at home according to the study protocol and gave signed consent for their data to be published in the scientific literature.

\section{Experimental protocol}

Participants received the experimental protocol and a kit containing the study materials through the mail. An electronic study protocol was also provided via email. The study kit included a Precision Xtra handheld glucose and ketone meter (Abbott Diabetes Care Inc., Almeda, CA) with

\begin{tabular}{lccccc}
\multicolumn{7}{l}{ TABLE 1: Participant demographics. } \\
\hline Participant no. & Sex & Age & Height $(\mathbf{c m})$ & Weight $(\mathrm{kg})$ & BMI $\left(\mathbf{k g} / \mathbf{m}^{2}\right)$ \\
\hline 1 & M & 34 & 189.0 & 81.8 & 22.9 \\
2 & F & 25 & 171.0 & 61.0 & 20.9 \\
3 & M & 45 & 170.2 & 65.9 & 22.7 \\
4 & M & 40 & 175.3 & 72.7 & 22.5 \\
5 & M & 46 & 185.4 & 71.8 & 20.9 \\
6 & M & 41 & 180.3 & 73.5 & 22.6 \\
7 & M & 42 & 160.0 & 61.4 & 24.0 \\
8 & M & 29 & 182.0 & 79.0 & 23.8 \\
9 & M & 43 & 190.5 & 88.6 & 24.4 \\
10 & M & 34 & 190.5 & 106.8 & 29.4 \\
11 & F & 24 & 162.6 & 43.2 & 16.3 \\
\hline
\end{tabular}

Source: Authors' own work

BMI, Body Mass Index; M, male; F, female.
10 ketone strips to measure blood levels of BHB. A Meridian Valley Glucose Tolerance Insulin Response (Blood Spot) measurement kit (\#8069, Meridian Valley Lab, Tukwila, WA) was also included, as was a $25 \mathrm{~g}$ pre-weighed pouch of PHAT FIBRE (PF) (Nourish Balance Thrive, Redding, CA). $\mathrm{PF}$ is a newly-developed proprietary sports supplement powder consisting of MCT oil suspended in digestionresistant maltodextrin. To minimise the likelihood of adverse reactions to $\mathrm{PF}$, it is packaged in a gluten-free, dairy-free and peanut-free facility. A $25 \mathrm{~g}$ serving of PF contains $9.4 \mathrm{~g}$ carbohydrate ( $0.2 \mathrm{~g}$ sugars, $8.8 \mathrm{~g}$ fibre) and $15.2 \mathrm{~g}$ fat. The MCT oil-derived fat consisted of C6:0 (caproic acid, up to $20 \%$ ), C8:0 (caprylic acid, minimum 50\%) and C10:0 (capric acid, minimum 30\%).

After an overnight fast of at least $8 \mathrm{~h}$ (but not more than $16 \mathrm{~h}$ ), participants were instructed to follow the manufacturer's instructions for the Meridian Valley Kraft Assay, using $25 \mathrm{~g}$ of PF dissolved in 250-300 $\mathrm{ml}$ of water instead of the $100 \mathrm{~g}$ of dextrose normally used for this test (not included in the study kit). This assay measures insulin and glucose responses over $4 \mathrm{~h}$, determining levels from blood spots on filter paper using enzymatic (glucose) and immuno (insulin) assays. For this study, blood spots were taken on filter paper at baseline, as well as $30 \mathrm{~min}, 1 \mathrm{~h}, 2 \mathrm{~h}, 3 \mathrm{~h}$ and $4 \mathrm{~h}$ after consuming $25 \mathrm{~g}$ of PF. Participants were advised to avoid strenuous exercise and any other caloric intake during the study period. At each time point, participants also measured and documented their own blood BHB measurements using the Precision Xtra meter.

Throughout the study, as well as the following day, subjective data were collected on satiety, cognitive function, alertness and GI symptoms, using questions that were answered on an analogue scale ranging from 1 (not at all) to 5 (very much). A sample of the questions from the study protocol is provided in Figure 1. An online pro forma was provided for each time point to allow data (BHB levels, activities over the preceding hour and subjective measures) to be collected from the participants in real time. An electronic timestamp was automatically recorded when pro formas were submitted to ensure that each measurement and the associated data were collected and recorded in line with the study protocol. Demographic data, blood BHB levels and subjective data were then collected directly from the online pro formas. After allowing the blood spots to dry overnight, participants shipped their filter papers to Meridian Valley Lab for glucose and insulin measurements, according to the manufacturer's instructions.

\section{Blood glucose measurements}

Once blood spot data had been collected, it became apparent that blood glucose measurements taken from the filter paper were lower than expected, with a median (range) fasting glucose measurement of $70 \mathrm{mg} / \mathrm{dl}(49 \mathrm{mg} / \mathrm{dl}-88 \mathrm{mg} / \mathrm{dl})$ 


\begin{tabular}{lllllll} 
Over the last hour: & & & & & \\
\hline 1. I have had more gas than usual & 1 & 2 & 3 & 4 & 5 \\
2. I have been in a good mood & 1 & 2 & 3 & 4 & 5 \\
3. I have felt more irritable than usual & 1 & 2 & 3 & 4 & 5 \\
4. I have felt full (satisfied) & 1 & 2 & 3 & 4 & 5 \\
5. I have felt shakier than usual & 1 & 2 & 3 & 4 & 5 \\
6. I have felt more alert & 1 & 2 & 3 & 4 & 5 \\
7. I have been less able to think clearly & 1 & 2 & 3 & 4 & 5 \\
8. I have been more tired (sleepier) than usual & 1 & 2 & 3 & 4 & 5 \\
9. I have been thinking more clearly than usual & 1 & 2 & 3 & 4 & 5 \\
10. I have felt more anxious than usual & 1 & 2 & 3 & 4 & 5 \\
11. My stomach rumbled more than usual & 1 & 2 & 3 & 4 & 5 \\
12. I have had loose stools & 1 & 2 & 3 & 4 & 5 \\
13. I have been hungry & 1 & 2 & 3 & 4 & 5 \\
14. I have been more easily distracted than usual & 1 & 2 & 3 & 4 & 5 \\
15. I have been more abdominal pain than usual & 1 & 2 & 3 & 4 & 5 \\
16. I have felt focused & 1 & 2 & 3 & 4 & 5 \\
17. My hunger has distracted me & 1 & 2 & 3 & 4 & 5 \\
18. I have felt nauseated & 1 & 2 & 3 & 4 & 5
\end{tabular}

Source: Authors' own work

Note: Every hour after consuming PF during the study period $(4 \mathrm{~h})$, each participant answered these 18 questions on a scale of 1 (not at all) to 5 (very much).

FIGURE 1: Subjective measures questionnaire.

across the 11 subjects. During the study, two subjects had taken simultaneous blood glucose measurements using a handheld glucometer (Precision Xtra; Abbott Diabetes Care Inc., Almeda, CA), with the glucose level on the handheld glucometer being on average (median with 95\% CI) $26 \mathrm{mg} / \mathrm{dl}$ (14 mg/dl-36 mg/dl, $n=12$ ) higher than the blood spot value. One participant also performed the Meridian Kraft Insulin assay after drinking $100 \mathrm{~g}$ of glucose solution, according to the manufacturer's instructions. Therefore, 18 data points ( 3 assays, 6 time points per assay) ranging from $72 \mathrm{mg} / \mathrm{dl}$ to $200 \mathrm{mg} / \mathrm{dl}$ (on the handheld meter) were available to compare values taken from the blood spot filter paper assay with a blood glucose measurement taken at the same time as the blood spot was collected. Linear regression analysis showed that the two were significantly correlated $\left(R^{2}=0.83, p<0.0001\right)$, so the resulting regression equation was used to create a 'calibration curve' and calculate estimated blood glucose measurements from blood spot results for all participants.

\section{Product development}

As part of ongoing pilot experiments, one participant (\#4) repeated the study using an updated formulation of PHAT FIBRE (PFv2), measuring both blood glucose and BHB using a handheld glucose and ketone meter, as described above. PFv2 was formulated to include 70\% C8:0 (caprylic acid) triglycerides by weight, suspended in $30 \%$ digestion-resistant maltodextrin.

\section{Statistical analysis}

Statistical analyses were performed using SPSS software version 22 (SPSS Inc., Chicago, IL) and GraphPad Prism version 7 (GraphPad Software, La Jolla, CA). For subjective measures, answers were converted to their numerical equivalent for graphical representation and statistical analysis. Metabolic data did not consistently follow a normal distribution and were therefore analysed using nonparametric methods. Within-subject pairwise comparisons of dependent variables (i.e. blood glucose, insulin and BHB) at certain time points were compared to the individual's fasting baseline measurement using the Wilcoxon signed-rank test. A $p$-value of $<0.05$ was considered statistically significant.

\section{Results Included data}

All participants completed the study in full. Based on the electronic time stamps, mean (standard deviation) time between hourly time points was $60.7( \pm 6.2) \mathrm{min}$, suggesting good adherence to the study protocol. For the duration of the study, all participants documented normal household and work activities that would not be expected to result in large changes in insulin, glucose or BHB. One male participant (\#10) had their blood spot card inappropriately handled by the laboratory, and their glucose and insulin levels were not available. Metabolic parameters from this participant were therefore excluded from the analysis. Two other participants (\#1 and \#9) provided blood spots that were considered low quality by the laboratory due to small blood volumes. However, the samples were still large enough to provide data for analysis. In addition, nine participants had at least one insulin level below the detection limit of the immunoassay $(<2 \mu \mathrm{U} / \mathrm{ml})$. These samples were assigned an insulin level of $1 \mu \mathrm{U} / \mathrm{ml}$ to allow for statistical analysis.

\section{Subjective measures}

None of the participants reported a significant effect of PF on irritability or negative affect: shakiness, sleepiness, distractibility, anxiety, loose stools, abdominal pain or nausea. Median hunger score was 1 ('not at all' hungry) for the first $2 \mathrm{~h}$ of the study, increasing to a median score of 2 ('a little bit' hungry) at $3 \mathrm{~h}$ and $4 \mathrm{~h}$ (Figure 2a). This corresponded with a median satiety (fullness) score of 3 ('somewhat' full) at $1 \mathrm{~h}$ and $2 \mathrm{~h}$, which decreased to a score of 2 ('a little bit' full) at $3 \mathrm{~h}$ and $4 \mathrm{~h}$ (Figure 2b). Participants reported a median focus score of 3 ('somewhat' focused) throughout the entire study period (Figure 2d).

\section{Glucose responses to PHAT FIBRE}

Based on the data reported by the laboratory, median (95\% CI) glucose at baseline was $70 \mathrm{mg} / \mathrm{dl}(49 \mathrm{mg} / \mathrm{dl}-80 \mathrm{mg} / \mathrm{dl})$. Blood glucose increased by $9 \mathrm{mg} / \mathrm{dl} 30 \mathrm{~min}$ after consuming $\mathrm{PF}$ to $79 \mathrm{mg} / \mathrm{dl}(61 \mathrm{mg} / \mathrm{dl}-103 \mathrm{mg} / \mathrm{dl})$, which was statistically significant $(p=0.002)$. However, as described in the methods above, it appeared that the enzymatic assay tended to underestimate blood glucose values, so a linear regression equation was used to adjust the results based on a subset of data for which a blood glucose measurement was also available from the handheld glucometer (Figure 3). Blood glucose results were therefore adjusted based on the equation: $\mathrm{Y}=0.6927 * \mathrm{X}+45.04$. 


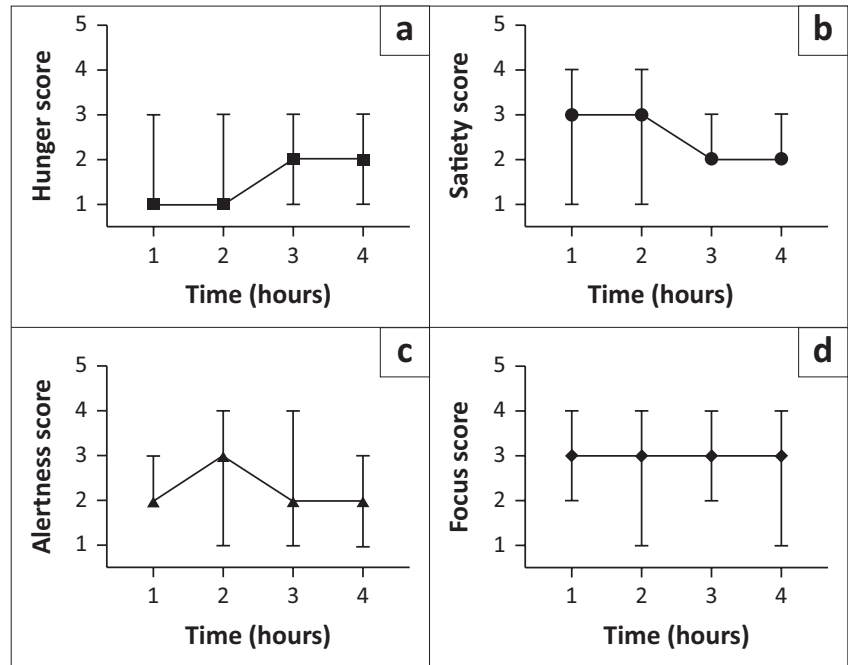

Source: Authors' own work

Note: None of the participants reported a significant effect of PF on irritability, mood, shakiness, sleepiness, distractibility, anxiety, loose stools, abdominal pain or nausea. Plots display median (range): a-d

FIGURE 2: Subjective measures of mood, satiety and hunger: (a) score for hunger, (b) satiety, (c) feeling more alert and (d) focus.

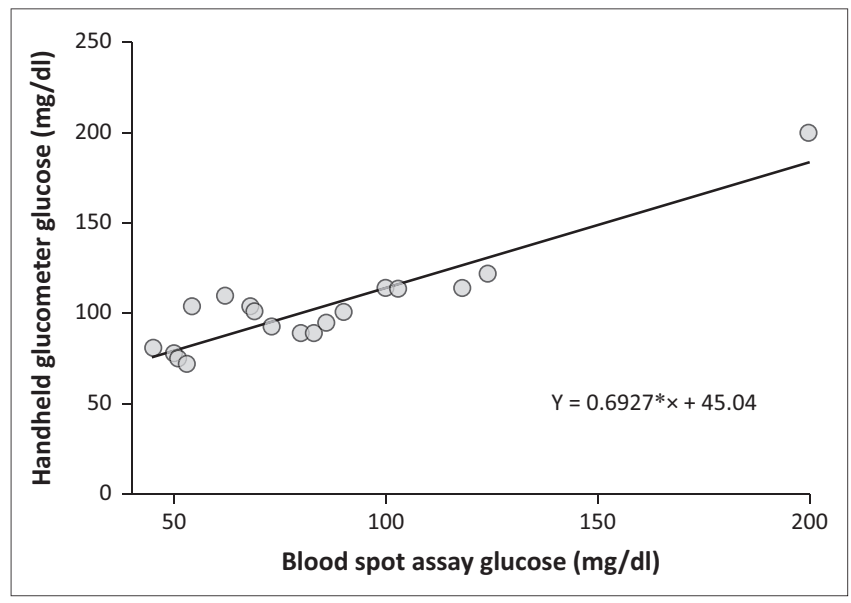

Source: Authors' own work

FIGURE 3: Blood glucose calibration. Linear regression of 18 data points where data were available for both the blood spot enzymatic assay and a handheld glucometer. The single point at $200 \mathrm{mg} / \mathrm{dl}$ is from one participant (\#4) who had data using the same assay after a $100 \mathrm{~g}$ glucose load. A significant correlation between the two $\left(R^{2}=0.83, p<0.0001\right)$ was seen, and the resulting equation $(\mathrm{Y}=0.6927 * \mathrm{X}+45.04)$ was used to adjust glucose measurements for all participants in the analysis.

For the adjusted blood glucose results, median (95\% CI) glucose at baseline was $94 \mathrm{mg} / \mathrm{dl}(79 \mathrm{mg} / \mathrm{dl}-101 \mathrm{mg} / \mathrm{dl})$. This increased by $6 \mathrm{mg} / \mathrm{dl}$ to $100 \mathrm{mg} / \mathrm{dl}(87 \mathrm{mg} / \mathrm{dl}-116 \mathrm{mg} /$ $\mathrm{dl})$, which was statistically significant $(p=0.002)$. Blood glucose returned to baseline by $1 \mathrm{~h}$ and remained similar to baseline for the remainder of the experimental period. Individual glucose responses for the first hour, and aggregated data over the 4 -h study period, are shown in Figure 4.

\section{Insulin responses to PHAT FIBRE}

Median (95\% CI) insulin level was $2.1 \mu \mathrm{U} / \mathrm{ml}(1.0 \mu \mathrm{U} / \mathrm{ml}-$ $7.6 \mu \mathrm{U} / \mathrm{ml})$ at baseline, which increased by $4.6 \mu \mathrm{U} / \mathrm{ml}$ to $6.7 \mu \mathrm{U} / \mathrm{ml}(1.0 \mu \mathrm{U} / \mathrm{ml}-8.9 \mu \mathrm{U} / \mathrm{ml})$ after $30 \mathrm{~min}$. However, this difference was not statistically significant. Median

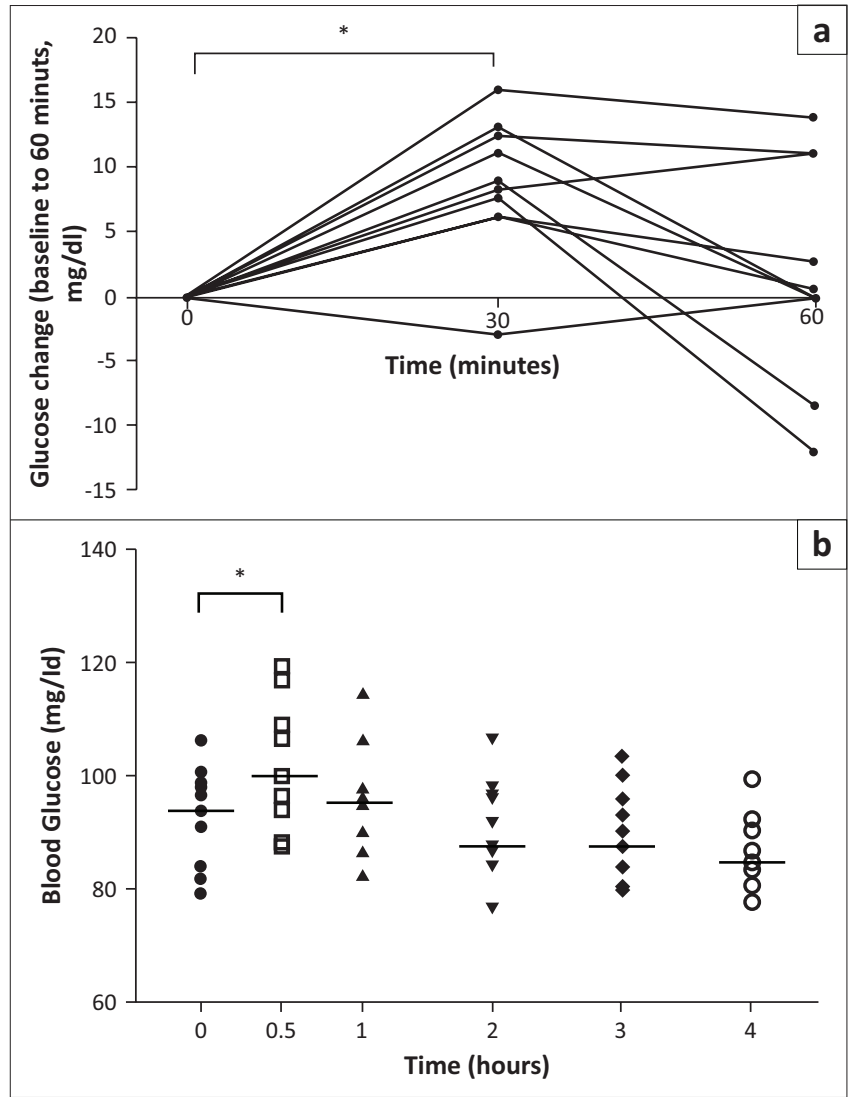

Source: Authors' own work

FIGURE 4: Blood glucose responses to PF. (a) Adjusted individual blood glucose changes (from baseline) at $30 \mathrm{~min}$ and $60 \mathrm{~min}$. The magnitude of blood glucose change at $30 \mathrm{~min}$ ranged from $-2.8 \mathrm{mg} / \mathrm{dl}$ to $+16.0 \mathrm{mg} / \mathrm{dl}$. In $70 \%$ of participants, glucose had returned to baseline by $60 \mathrm{~min}$. (b) Scatter plot (line at median) of blood glucose at baseline (fasting) and across the 4-h study period. Median $(95 \% \mathrm{Cl})$ blood glucose after $30 \mathrm{~min}$ had increased from $94 \mathrm{mg} / \mathrm{dl}(79 \mathrm{mg} / \mathrm{dl}-101$ $\mathrm{mg} / \mathrm{dl})$ to $100 \mathrm{mg} / \mathrm{dl}(87 \mathrm{mg} / \mathrm{dl}-116 \mathrm{mg} / \mathrm{dl})$, which was statistically significant $(p=0.002)$. Blood glucose returned to baseline by $1 \mathrm{~h}$ and remained similar to baseline for the remainder of the experimental period.

insulin fell to $1 \mu \mathrm{U} / \mathrm{ml}(1.0 \mu \mathrm{U} / \mathrm{ml}-6.1 \mu \mathrm{U} / \mathrm{ml})$ by $2 \mathrm{~h}$ and remained at $1 \mu \mathrm{U} / \mathrm{ml}$ for the remainder of the study period. Individual insulin responses for the first hour, and aggregated data over the 4-h study period, are shown in Figure 5.

\section{Beta-hydroxybutyrate responses to PHAT FIBRE}

Median (95\% CI) BHB at baseline was $0.3 \mathrm{mM}$ (0.2 mM-0.5 $\mathrm{mM})$, which increased by $0.2 \mathrm{mM}$ to $0.5 \mathrm{mM}(0.2 \mathrm{mM}-0.8$ $\mathrm{mM}$ ) after $30 \mathrm{~min}$. However, this difference was not statistically significant $(p=0.07)$. One outlier (participant \#8) had a fasting BHB of $1.1 \mathrm{mM}$, which fell to $0.9 \mathrm{mM}$ after 30 min. Excluding this outlier (leaving 10 participants who had a fasting BHB of $0.2 \mathrm{mM}-0.5 \mathrm{mM}), \mathrm{PF}$ significantly increased $\mathrm{BHB}$ at 30 min compared to baseline $(p=0.02)$. Including all participants, median BHB decreased to $0.4 \mathrm{mM}(0.2 \mathrm{mM}-0.6$ $\mathrm{mM})$ at $1 \mathrm{~h}$, but increased again to $0.5 \mathrm{mM}(0.4 \mathrm{mM}-0.6 \mathrm{mM})$ at both $2 \mathrm{~h}$ and $3 \mathrm{~h}$ and $0.45 \mathrm{mM}(0.4 \mathrm{mM}-0.6 \mathrm{mM})$ at $4 \mathrm{~h}$. At both $3 \mathrm{~h}$ and $4 \mathrm{~h}, \mathrm{BHB}$ was significantly elevated compared to fasting baseline levels ( $p=0.03$ and $p=0.002$, respectively). Individual $\mathrm{BHB}$ responses for the first hour, and aggregated data over the 4-h study period, are shown in Figure 6. No correlation between degree of glucose or insulin response and degree of $\mathrm{BHB}$ response was seen. 

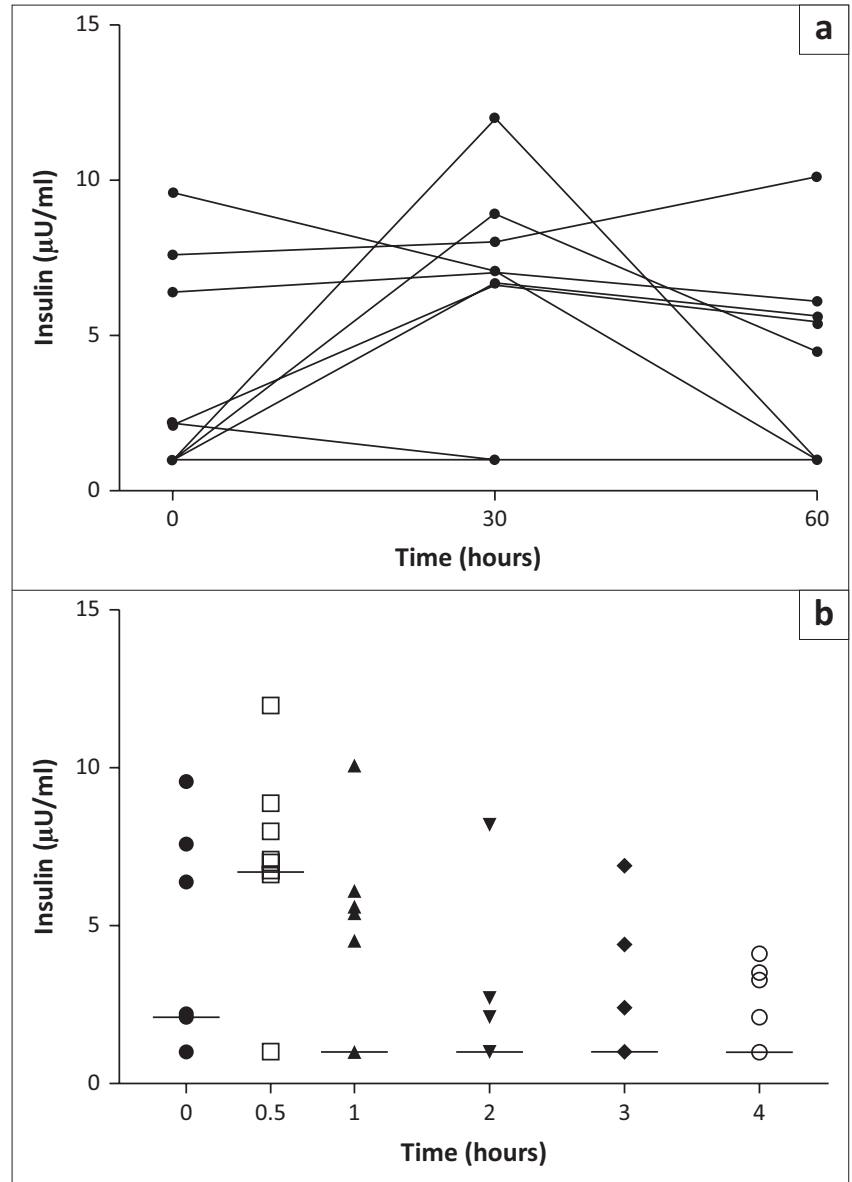

Source: Authors' own work

FIGURE 5: Insulin responses to PF. (a) Individual insulin changes (from baseline) at $30 \mathrm{~min}$ and $60 \mathrm{~min}$. The magnitude of insulin change at $30 \mathrm{~min}$ ranged from $-2.5 \mu \mathrm{U} / \mathrm{ml}$ to $+11.0 \mu \mathrm{U} / \mathrm{ml}$. (b) Scatter plot (line at median) of insulin levels at baseline (fasting) and across the 4 -h study period. Median $(95 \% \mathrm{Cl})$ insulin after $30 \mathrm{~min}$ had increased from $2.1 \mu \mathrm{U} / \mathrm{ml}(1.0 \mu \mathrm{U} / \mathrm{ml}-7.6 \mu \mathrm{U} / \mathrm{ml})$ to $6.7 \mu \mathrm{U} / \mathrm{ml}$ $(1.0 \mu \mathrm{U} / \mathrm{ml}-8.9 \mu \mathrm{U} / \mathrm{ml})$. However, this change was not significantly different (Wilcoxon signed rank test, $p=0.2$ ).

\section{Glucose and beta-hydroxybutyrate responses to PFv2}

In a single participant (\#4), $25 \mathrm{~g}$ of PFv2 did not elevate blood glucose from a baseline of $88 \mathrm{mg} / \mathrm{dl}$. This is in contrast to a large $25 \mathrm{mg} / \mathrm{dl}$ glucose response seen in this participant after $25 \mathrm{~g}$ of PFv1, from a baseline of $89 \mathrm{mg} / \mathrm{dl}$ to $114 \mathrm{mg} / \mathrm{dl}$ at 30 min (Figure 7a). A greater BHB response was seen with PFv2 compared to PFv1, increasing from $0.2 \mathrm{mM}$ at baseline to 0.7 $\mathrm{mM}$ after $30 \mathrm{~min}$, reaching a peak of $0.8 \mathrm{mM}$ at $2 \mathrm{~h}$ and remaining above $0.5 \mathrm{mM}$ for the whole study period (Figure 7b).

\section{Discussion}

In the field of endurance sports, the nutritional approaches used to optimally fuel performance are undergoing a paradigm shift. In dramatic opposition to the highcarbohydrate diets and frequent 'carb-loading' strategies previously used by endurance athletes, many elite longdistance runners, triathletes and cyclists are now employing regular carbohydrate restriction, including during races, to improve performance. ${ }^{8,20,21}$ This approach was largely pioneered by the work of Jeff Volek and Stephen Phinney, as

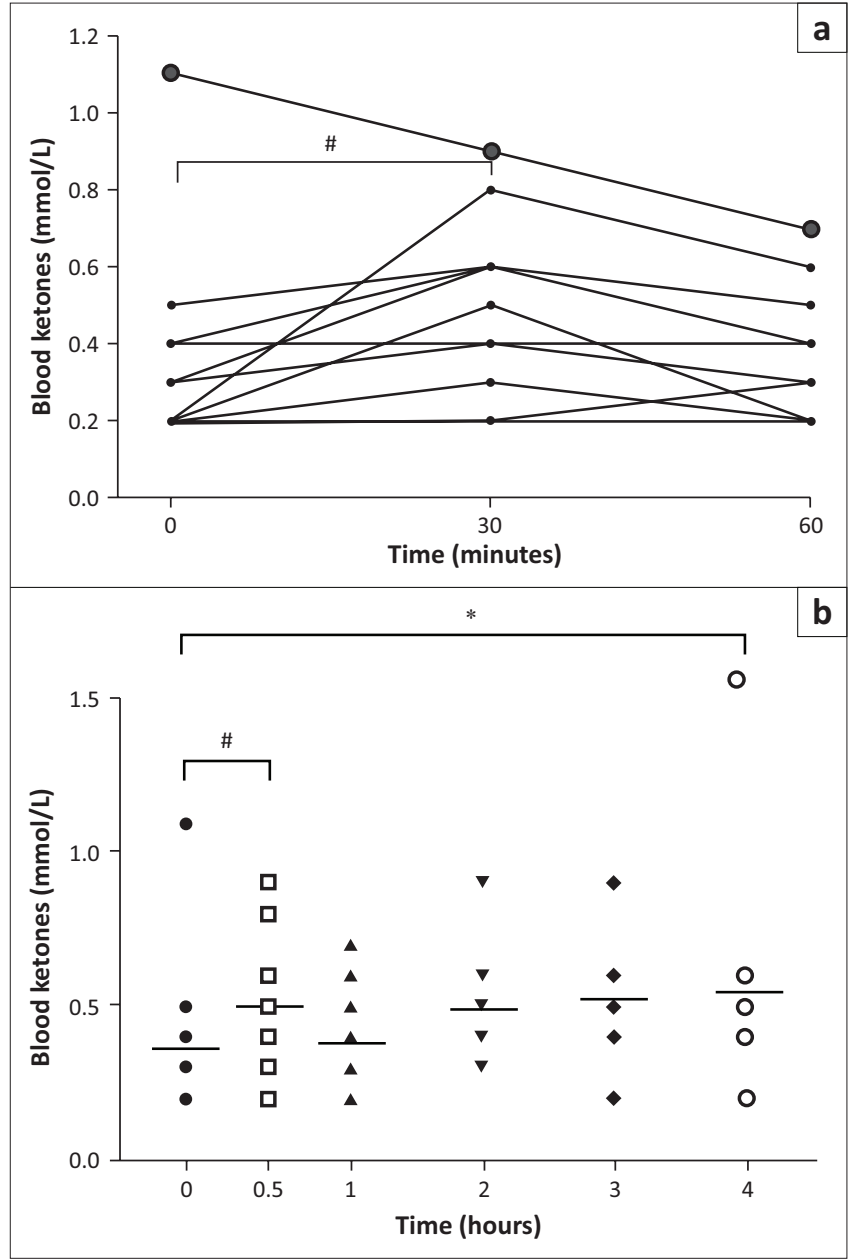

Source: Authors' own work

FIGURE 6: Beta-hydroxybutyrate responses to PF. (a) Individual BHB changes (from baseline) at $30 \mathrm{~min}$ and $60 \mathrm{~min}$. The magnitude of BHB change at $30 \mathrm{~min}$ ranged from $-0.2 \mathrm{mmol} / \mathrm{L}$ to $+0.6 \mathrm{mmol} / \mathrm{L}$. (b) Scatter plot (line at median) of insulin levels at baseline (fasting) and across the 4-h study period. Median (95\% Cl) BHB after $30 \mathrm{~min}$ had increased from $0.3 \mathrm{mmol} / \mathrm{L}(0.2 \mathrm{mmol} / \mathrm{L}-0.5 \mathrm{mmol} / \mathrm{L})$ to $0.5 \mathrm{mmol} / \mathrm{L}(0.2 \mathrm{mmol} / \mathrm{L}-0.8 \mathrm{mmol} / \mathrm{L})$. At $4 \mathrm{~h}$, median BHB was $0.45 \mathrm{mM}(0.4$ $\mathrm{mM}-0.6 \mathrm{mM})$. \#Indicates significantly increased BHB $(p=0.02)$ at $30 \mathrm{~min}$ compared to baseline, after exclusion of a single outlier (indicated by open grey circles in a). *Indicates whole-group significant increase in $\mathrm{BHB}$ at $3 \mathrm{~h}$ and $4 \mathrm{~h}$ compared to baseline ( $p=0.3$ and $p=0.002$, respectively).

well other high-profile medical doctors such as Timothy Noakes and Philip Maffetone. ${ }^{1,22,23}$ As such, there is increasing interest in supplements that can be used to fuel prolonged endurance efforts without large increases in blood glucose and insulin that would suppress endogenous fatty acid oxidation. Here, we show that $25 \mathrm{~g}$ of a powdered MCT oilbased sport supplement $(\mathrm{PF})$ in resting healthy participants can significantly increase blood BHB levels with a less than $10 \%$ increase in blood glucose and without significantly affecting insulin levels. In a single participant, further development of the product resulted in even greater increases in BHB with no change in blood glucose.

During prolonged endurance exercise, especially events of moderate intensity (i.e. up to $\approx 50 \%$ of $\mathrm{VO}_{2} \mathrm{Max}$ ), aerobic fat metabolism provides at least $50 \%$ of total energy expenditure (TEE). ${ }^{24}$ The energy contribution from fat oxidation then decreases dramatically as intensity increases above $60 \%$ of $\mathrm{VO}_{2} \mathrm{Max}$. However, extended periods of low-carbohydrate 

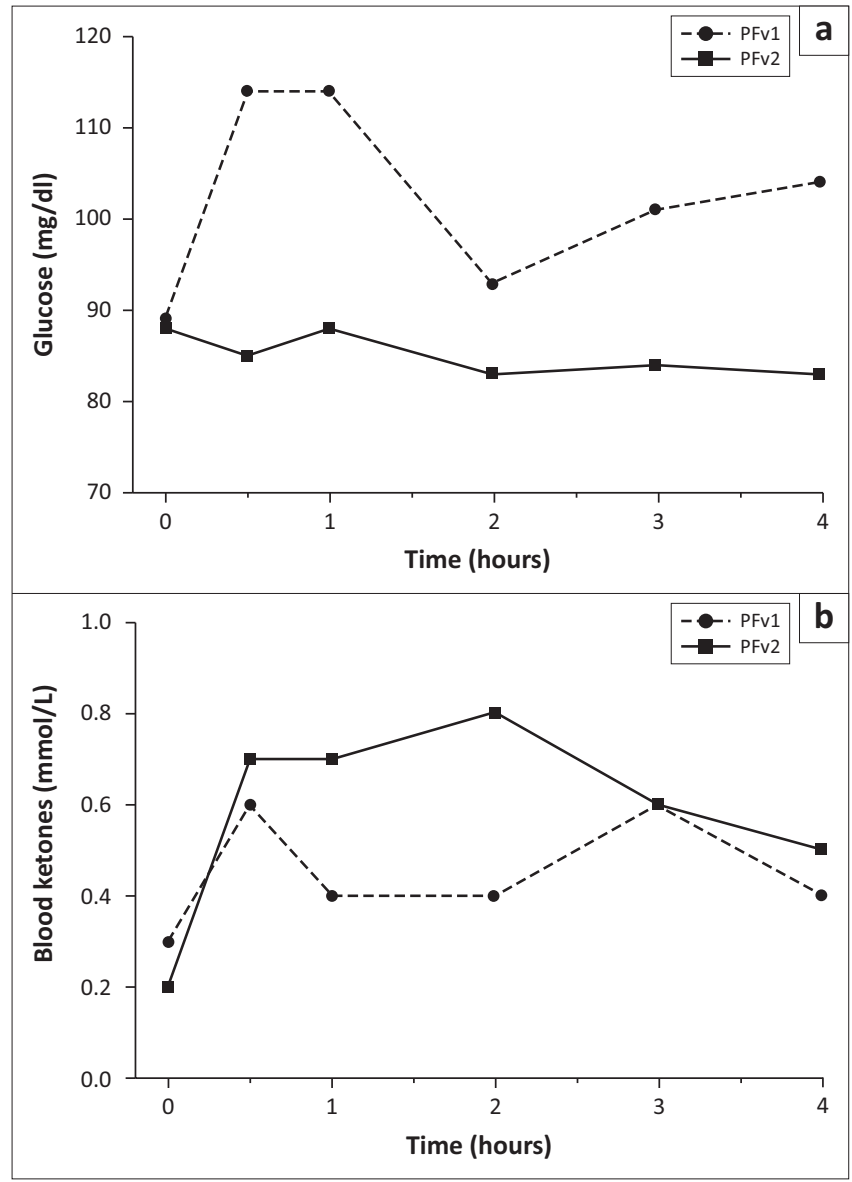

Source: Authors' own work

FIGURE 7: Glucose and BHB responses to PFv2. (a) In participant \#4, who had displayed the greatest blood glucose response to PFv1, $25 \mathrm{~g}$ of PFv2 did not elevate blood glucose from a baseline of $88 \mathrm{mg} / \mathrm{dl}$. (b) A greater BHB response was seen with PFv2 compared to PFv1. After $25 \mathrm{~g}$ of PFv2, BHB increased by 0.5 $\mathrm{mmol} / \mathrm{L}$ from $0.2 \mathrm{mmol} / \mathrm{L}$ at baseline to $0.7 \mathrm{mmol} / \mathrm{L}$ after $30 \mathrm{~min}$, reached a peak of $0.8 \mathrm{mmol} / \mathrm{L}$ at $2 \mathrm{~h}$ and remained above $0.5 \mathrm{mmol} / \mathrm{L}$ for the whole study period.

keto-adaptation in endurance athletes have recently been shown to result in the capacity to perform peak fat oxidation at over $80 \%$ of $\mathrm{VO}_{2} \mathrm{Max}^{8}$ In the same study, aerobic fat metabolism provided an average $88 \%$ of TEE during a 180 min treadmill run at $65 \%$ of $\mathrm{VO}_{2} \mathrm{Max}$ in a group of 10 elite ultra-marathoners and ironman distance triathletes habituated on a low-carbohydrate diet $(<10 \%$ of calories from carbohydrate). ${ }^{8}$ The keto-adapted athletes displayed greater ketone and glycerol levels during prolonged exercise compared to athletes eating a carbohydrate-based diet, despite similar circulating levels of insulin and glucose. ${ }^{8}$ The increase in capacity to metabolise fat at higher intensities is therefore likely to be due to metabolic changes such as upregulation of pathways involved in aerobic fatty acid metabolism, as well as selective changes in tissue insulin sensitivity. Restricting carbohydrates may also result in greater glycogen depletion, increasing AMPK activation and promoting pathways associated with mitochondrial biogenesis. ${ }^{21,25}$ However, other data suggest that endurance exercise itself is the largest stimulus for mitochondrial biogenesis regardless of carbohydrate timing ${ }^{26}$ and that the signalling benefits of training in a carbohydrate-restricted state may be enhanced by consuming a carbohydrate source during the recovery period. ${ }^{21}$ Other than the signalling effects of lower carbohydrate availability during exercise, the antiinflammatory and epigenetic (via histone deacetylase inhibition) effects of elevated ketone bodies such as BHB after carbohydrate restriction may provide other beneficial adaptations for the endurance athlete. ${ }^{27,28}$

Despite a greater contribution of fatty acids to TEE during aerobic exercise, keto-adapted athletes deplete muscle glycogen at a similar rate to athletes consuming a carbohydrate-based diet. ${ }^{8}$ This suggests that a carbohydrate source is still required during prolonged exercise in these athletes. In this study, a $25 \mathrm{~g}$ dose of PF resulted in a small (median $6 \mathrm{mg} / \mathrm{dl}$ ) increase in blood glucose within $30 \mathrm{~min}$. The carbohydrate source in PF is therefore not entirely digestion resistant. However, the glucose response at $30 \mathrm{~min}$ was highly variable between participants, ranging from -2.8 $\mathrm{mg} / \mathrm{dl}$ to $+16.0 \mathrm{mg} / \mathrm{dl}$. This may be due to differences in glycogen levels and insulin sensitivity after an overnight fast, or occur as a result of differences in genetics and the gut microbiota affecting metabolic responses to carbohydrate..$^{29}$ Additionally, one participant (\#3) reported drinking black coffee during the second hour of the study. Caffeinated coffee has been shown to acutely increase blood glucose, ${ }^{30}$ and this participant also had the highest blood glucose levels at both $2 \mathrm{~h}(106 \mathrm{mg} / \mathrm{dl})$ and $3 \mathrm{~h}(103 \mathrm{mg} / \mathrm{dl})$.

Although PF was originally intended to not include a significant source of glucose, a small glycaemic load may actually be of benefit to the low-carb endurance athlete if provided before or during exercise. One major use of glucose during exercise in athletes consuming a low-carbohydrate diet is the regeneration of oxaloacetate (OAA) in the mitochondrial Kreb's cycle, a process known as anapleurosis. This occurs when mitochondrial acetyl-CoA accumulates, which increases the activity of pyruvate carboxylase. Pyruvate carboxylase diverts pyruvate from glycolysis to the production of OAA that can bind with acetyl-CoA to form citrate as the 'first step' of the Kreb's cycle. In the low-carb athlete, mitochondrial acetyl-CoA may accumulate in the skeletal muscle due to increased lipolysis and beta-oxidation of fatty acids, or as the result of increased ketone availability (transesterification and cleavage of acetoacetate to two molecules of acetyl-CoA). To help drive aerobic production of ATP, this acetyl-CoA must then bind to OAA. Adequate production of OAA is therefore a rate-limiting aspect of the ability to use fatty acids and ketone bodies as fuel during exercise. This is thought to be the reason why exogenous ketones (given as a ketone ester) have a greater performanceboosting effect when given with a source of glucose (Clarke K 2016, personal communication, October 13). ${ }^{13}$

As fat-adapted athletes do not appear to spare glycogen during exercise despite the majority of TEE coming from fatty acids, and exogenous ketone sources have a greater benefit when given with a source of carbohydrate, glucose availability in the muscle (either from glycogen stores or from an exogenous source) still has the potential to be a ratelimiting factor to performance in the low-carb athlete. 
One other product, a hydrothermally processed corn starch (UCAN superstarch), has been specifically marketed to athletes eating a low-carbohydrate diet for this reason. ${ }^{9}$ As well as providing a low glycaemic index carbohydrate source, similar to that used in UCAN, one potential benefit of $\mathrm{PF}$ is that that majority of calories come from MCTs, which can boost endogenous ketone levels. In this manner, PF provides an anapleurotic substrate and ketone source together. However, as with the blood glucose response, $\mathrm{BHB}$ responses to $\mathrm{PF}$ were highly variable, ranging from -0.2 $\mathrm{mmol} / \mathrm{L}$ to $+0.6 \mathrm{mmol} / \mathrm{L}$ after $30 \mathrm{~min}$. Excluding the results from one outlier (participant \#8) who had a fasting BHB of 1.1 $\mathrm{mmol} / \mathrm{L}, \mathrm{PF}$ resulted in a significant increase in $\mathrm{BHB}$, with a median response of $+0.2 \mathrm{mmol} / \mathrm{L}$. As $25 \mathrm{~g}$ of $\mathrm{PF}$ contains around $15 \mathrm{~g}$ of MCTs, this increase in BHB is about as much as would be predicted. ${ }^{3}$ The data also suggest that there is a cut-off level of BHB somewhere between $0.5 \mathrm{mmol} / \mathrm{L}$ and 1.0 $\mathrm{mmol} / \mathrm{L}$ where consuming PF will either increase BHB (due to provision of MCTs as a source of ketones) or decrease $\mathrm{BHB}$ (due to the provision of an anapleurotic substrate). However, other factors such as insulin sensitivity and glucose transporter activity will also be involved, as the individual $\mathrm{BHB}$ response was not correlated with concurrent changes in glucose or insulin levels. The dynamics of the $\mathrm{BHB}$ response to PF agrees with data from other studies, which show a biphasic response after consuming MCTs. For instance, portal vein medium-chain fatty acid levels peak at $15 \mathrm{~min}$ and 75-90 min after infusion of MCTs into the GI tract of pigs, ${ }^{31}$ and blood BHB levels peak around $30 \mathrm{~min}$ and $3 \mathrm{~h}$ after MCT consumption in humans. ${ }^{32}$ This is the same pattern seen in this study. However, the BHB response to MCT consumption also appears to be greater after a period of regular MCT consumption. $^{31}$ Different degrees of habitual MCT consumption may therefore account for some of the variability in BHB responses between participants. Although the early (30 min) BHB peak is likely to be solely due to PF, the late $(3-4 \mathrm{~h})$ increase in BHB may also in part be due to a prolonged period of fasting overnight followed by consuming only around $150 \mathrm{kcal}$ of energy, most of which was fat.

To provide an optimal fuel source for low-carb or ketoadapted athletes during exercise, any supplement should have minimal effects on insulin levels, as endogenous lipolysis must still be allowed to contribute the majority of TEE. Consuming PF resulted in a small but non-significant increase in insulin after $30 \mathrm{~min}$, with the response ranging from $-2.5 \mu \mathrm{U} / \mathrm{ml}$ to $+11.0 \mu \mathrm{U} / \mathrm{ml}$. The degree of insulin response appeared to be associated with fasting insulin level, with minimal responses seen in those with a fasting insulin level above $5 \mu \mathrm{U} / \mathrm{ml}$ (but below $10 \mu \mathrm{U} / \mathrm{ml}$ ). Aside from one participant (\#1), insulin remained below $10 \mu \mathrm{U} / \mathrm{ml}$ throughout. This is the approximate level at which lipolysis is thought to be maximally suppressed in healthy individuals. ${ }^{15,33}$ However, it is worth considering that glucose and insulin levels both decrease during endurance exercise, even when a high glycaemic index carbohydrate source is administered. ${ }^{9}$ Therefore, both insulin and glucose responses to PF would be smaller if given during exercise. Despite this, there are a number of scenarios where a supplement that results in greater ketone production and a smaller glycaemic effect would be beneficial. This was the reason behind the development of PFv2. In separate trials by one participant, reducing the digestion-resistant maltodextrin content by $40 \%$ and changing the MCT source to predominantly caprylic acid (C8:0) doubled the maximal increase in BHB without affecting blood glucose. This suggests that PFv2 would also be suitable as an MCT powder to support ketogenic diets where maintenance of lower blood glucose levels is important, such as for certain cancers or neurological diseases. ${ }^{34}$ MCT-based products may also be useful in supporting the loss of excess adipose tissue, as MCTs have been shown to both decrease appetite and increase dietinduced thermogenesis. ${ }^{35,36,37}$ One significant benefit of the PF formulation is that no participant reported any negative GI symptoms, which are the most frequently reported side effects of MCT consumption. ${ }^{3}$ This supports the idea that MCTs are better tolerated when delivered as a powder.

This study does have some limitations. Firstly, this was a series of open-label pilot studies, and therefore, the participants were not blinded. While it is likely that the acute metabolic effects were due to $\mathrm{PF}$, the nature of the study may have prevented the participants from openly reporting negative subjective side effects. Although generally considered to be the standard measure of blood ketone levels, using blood BHB to determine the ketogenic capacity of an intervention gives an incomplete picture. Absolute $\mathrm{BHB}$ levels are a dynamic sum of ketone production (in the liver), usage (in the peripheral tissues) and wastage (i.e. in the urine and breath). Other factors such as the hepatic NAD+/NADH ratio will determine the relative abundances of $\mathrm{BHB}$ and acetoacetate (AcAc, which can also be decarboxylated to acetone), ${ }^{38}$ the latter of which is less routinely measured in the blood outside of the laboratory setting. Importantly, as support increases for the use of performance-enhancing supplements that increase ketone levels exogenously, ${ }^{39}$ it is worth noting that the pure elevation of blood BHB levels is not the goal of supplementation - any additional ketone bodies must also be readily available as an efficient metabolic substrate. In the case of supplements such as PF, the goal is to provide a readily oxidisable calorie source that does not negatively affect the athlete's underlying physiology. As ketones are actively transported into the exercising muscle to support aerobic work, ${ }^{11}$ and the enzymes of ketolysis are upregulated by endurance exercise, ${ }^{39}$ it is likely that PF can provide a calorie source to support longer endurance efforts in the low-carb athlete without ever causing unnecessary deviations in blood glucose or BHB.

Another potential limitation is the fact that a linear regression had to be constructed to adjust the reported blood glucose results, as the glucose levels from the blood spots were spuriously low. A similar method has previously been used to reduce the error in the delayed measurement of blood glucose from filter paper, ${ }^{40}$ though there is an inherent error into this approach, as the calibration was based on 18 data points from only two individuals. A number of studies have shown that 
blood glucose levels on filter paper decrease over time and with increasing temperature, though they are generally thought to remain stable for up to seven days at room temperature. ${ }^{41,42}$ Time and conditions could therefore have promoted glucose degradation or increased erythrocyte metabolism of glucose in situ during transport of the blood spots back to the laboratory. Importantly, as paired statistical analyses were performed, all blood spots that were directly compared (i.e. from within the same participant) were exposed to the same transport conditions before analysis. Similarly, a number of insulin results had to be assigned an insulin result due to the level being below the detection limit of the assay. However, non-parametric analysis of the data means that the absolute glucose and insulin levels do not influence the results, as the analyses are based on ranks. Although the number of participants included is fairly standard for a study of this type, it is also possible that changes in insulin over the first hour of the study may have been significant if more participants were included. Finally, although the issues regarding participantled remote collection of samples resulted in some potential errors within the data, a strength of the study is that it was carried out in the participants' own homes rather than in a highly controlled laboratory setting. The study therefore captures the inherent variability that all people will experience when using supplements in the real world, which will require a degree of self-experimentation and monitoring to ensure optimal fuelling for individual performance.

In summary, we show that $25 \mathrm{~g}$ of an MCT oil-based sports supplement powder increases average BHB levels by 0.2 $\mathrm{mmol} / \mathrm{L}$ with only a small increase in blood glucose and without significantly increasing insulin levels. A revised formulation of the supplement resulted in twice the BHB response without affecting blood glucose. For the low-carb or keto-adapted athlete, both PF and PFv2 have the potential to support both ketone production and anapleurosis in order to help promote optimal substrate utilisation during exercise. Future studies will provide a larger dose of PFv2 and determine the metabolic responses during exercise compared to a placebo.

\section{Acknowledgements}

The authors would like to thank all the participants for their time and input to the study. They would also like to thank Ms. Amelia Luker for her assistance assembling study kits and collecting the study data, as well as Dr Elizabeth Nance for her input during the preparation of the manuscript.

\section{Competing interests}

Both T.R.W. and C.K. are employees of Nourish Balance Thrive and co-creators of PF and PFv2. All profits to date from the sales of PF were used to fund the current study.

\section{Authors' contributions}

C.K. recruited study participants, provided study materials and assisted in the preparation of the manuscript. T.R.W. designed the study protocol, performed the statistical analysis, and drafted and revised the manuscript.

\section{References}

1. Volek JS, Noakes T, Phinney SD. Rethinking fat as a fuel for endurance exercise. Eur J Sport Sci. 2015;15:13-20. https://doi.org/10.1080/17461391.2014.959564

2. Taubes $\mathrm{G}$. The science of obesity: What do we really know about what makes us fat? An essay by Gary Taubes. BMJ. 2013;346:f1050. https://doi.org/10.1136/bmj.f1050

3. Cunnane SC, Courchesne-Loyer A, Vandenberghe $\mathrm{C}$, et al. Can ketones help rescue brain fuel supply in later life? Implications for cognitive health during aging and the treatment of Alzheimer's disease. Front Mol Neurosci. 2016;9:53. https://doi. org/10.3389/fnmol.2016.00053

4. Storoni M, Plant GT. The therapeutic potential of the ketogenic diet in treating progressive multiple sclerosis. Mult Scler Int. 2015;2015:681289. https://doi. org/10.1155/2015/681289

5. Paoli A. Ketogenic diet for obesity: Friend or foe? Int J Environ Res Public Health 2014;11:2092-2107. https://doi.org/10.3390/ijerph110202092

6. Feinman RD, Pogozelski WK, Astrup A, et al. Dietary carbohydrate restriction as the first approach in diabetes management: Critical review and evidence base. Nutrition. 2015;31:1-13. https://doi.org/10.1016/j.nut.2014.06.011

7. Marquet L-A, Brisswalter J, Louis J, et al. Enhanced endurance performance by periodization of carbohydrate intake: 'Sleep Low' strategy. Med Sci Sports Exerc. 2016;48:663-672. https://doi.org/10.1249/MSS.0000000000000823

8. Volek JS, Freidenreich DJ, Saenz C, et al. Metabolic characteristics of keto-adapted ultra-endurance runners. Metabolism. 2016;65:100-110. https://doi.org/10. 1016/j.metabol.2015.10.028

9. Roberts MD, Lockwood C, Dalbo VJ, et al. Ingestion of a high-molecular-weight hydrothermally modified waxy maize starch alters metabolic responses to prolonged exercise in trained cyclists. Nutrition. 2011;27:659-665. https://doi. org/10.1016/j.nut.2010.07.008

10. Bach AC, Babayan VK. Medium-chain triglycerides: An update. Am J Clin Nutr. 1982;36:950-962.

11. Balasse EO, Féry F. Ketone body production and disposal: Effects of fasting, diabetes, and exercise. Diabetes Metab Rev. 1989;5:247-270. https://doi. org/10.1002/dmr.5610050304

12. Sato K, Kashiwaya $Y$, Keon CA, et al. Insulin, ketone bodies, and mitochondria energy transduction. FASEB J. 1995;9:651-658

13. Cox PJ, Kirk T, Ashmore T, et al. Nutritional ketosis alters fuel preference and thereby endurance performance in athletes. Cell Metab. 2016;24:256-268. https://doi.org/10.1016/j.cmet.2016.07.010

14. Furuyashiki T, Tanimoto $\mathrm{H}$, Yokoyama $\mathrm{Y}$, et al. Effects of ingesting highly branched cyclic dextrin during endurance exercise on rating of perceived exertion and blood components associated with energy metabolism. Biosci Biotechnol Biochem. 2014;78:2117-2119. https://doi.org/10.1080/09168451.2014.943654

15. Jensen MD, Caruso M, Heiling V, et al. Insulin regulation of lipolysis in nondiabetic and IDDM subjects. Diabetes. 1989;38:1595-1601. https://doi.org/10.2337/diab. 38.12.1595

16. Chassaing B, Koren O, Goodrich JK, et al. Dietary emulsifiers impact the mouse gut microbiota promoting colitis and metabolic syndrome. Nature. 2015;519:92-96. https://doi.org/10.1038/nature14232

17. Lerner A, Matthias T. Changes in intestinal tight junction permeability associated with industrial food additives explain the rising incidence of autoimmune disease. Autoimmun Rev. 2015;14:479-489. https://doi.org/10.1016/j.autrev. 2015.01.009

18. Chassaing B, Gewirtz AT. Has provoking microbiota aggression driven the obesity epidemic? BioEssays. 2016;38:122-128. https://doi.org/10.1002/bies.201500116

19. Sicherer SH, Sampson HA. Food allergy: Epidemiology, pathogenesis, diagnosis, and treatment. J Allergy Clin Immunol. 2014;133:291-307; quiz 8. https://doi. org/10.1016/j.jaci.2013.11.020

20. Maffetone PB, Laursen PB. Reductions in training load and dietary carbohydrates help restore health and improve performance in an Ironman triathlete. Int J Sports Sci Coach. 2017; Online publication ahead of print.

21. Impey SG, Hammond KM, Shepherd SO, et al. Fuel for the work required: A practical approach to amalgamating train-low paradigms for endurance athletes. Physiol Rep. 2016;4. pii: e12803. https://doi.org/10.14814/phy2.12803

22. Noakes T, Volek JS, Phinney SD. Low-carbohydrate diets for athletes: What evidence? $\mathrm{Br} J$ Sports Med. 2014;48:1077-1078. https://doi.org/10.1136/ bjsports-2014-093824

23. Maffetone PB, Laursen PB. Athletes: Fit but unhealthy? Sports Med Open 2015;2:24. https://doi.org/10.1186/s40798-016-0048-x

24. Egan B, Zierath JR. Exercise metabolism and the molecular regulation of skeletal muscle adaptation. Cell Metab. 2013;17:162-184. https://doi.org/10.1016/j. cmet.2012.12.012

25. Bartlett JD, Louhelainen J, Iqbal Z, et al. Reduced carbohydrate availability enhances exercise-induced p53 signaling in human skeletal muscle: Implications for mitochondrial biogenesis. Am J Physiol Regul Integr Comp Physiol. 2013;304:R450-R458. https://doi.org/10.1152/ajpregu.00498.2012

26. Jensen L, Gejl KD, Ørtenblad N, et al. Carbohydrate restricted recovery from long term endurance exercise does not affect gene responses involved in mitochondria biogenesis in highly trained athletes. Physiol Rep. 2015;3. pii: e12184. https://doi. org/10.14814/phy2.12184 
27. Shimazu T, Hirschey MD, Newman J, et al. Suppression of oxidative stress by betahydroxybutyrate, an endogenous histone deacetylase inhibitor. Science. 2013;339:211-214. https://doi.org/10.1126/science.1227166

28. Youm YH, Nguyen KY, Grant RW, et al. The ketone metabolite beta-hydroxybutyrate blocks NLRP3 inflammasome-mediated inflammatory disease. Nat Med. 2015;21:263-269.

29. Zeevi D, Korem T, Zmora N, et al. Personalized nutrition by prediction of glycemic responses. Cell. 2015;163:1079-1094. https://doi.org/10.1016/j.cell.2015.11.001

30. Robertson TM, Clifford MN, Penson S, et al. A single serving of caffeinated coffee impairs postprandial glucose metabolism in overweight men. $\mathrm{Br} J$ Nutr. 2015;114:1218-1225. https://doi.org/10.1017/S0007114515002640

31. Guillot $E$, Vaugelade $P$, Lemarchal $P$, et al. Intestinal absorption and liver uptake of medium-chain fatty acids in non-anaesthetized pigs. Br J Nutr. 1993;69(2):431442

32. Courchesne-Loyer A, Fortier M, Tremblay-Mercier J, et al. Stimulation of mild sustained ketonemia by medium-chain triacylglycerols in healthy humans: Estimated potential contribution to brain energy metabolism. Nutrition. 2013;29(4):635-640. https://doi.org/10.1016/j.nut.2012.09.009

33. Sonksen $\mathrm{P}$, Sonksen J. Insulin: Understanding its action in health and disease. $\mathrm{Br}$ Anaesth. 2000;85:69-79. https://doi.org/10.1093/bja/85.1.69

34. Meidenbauer JJ, Mukherjee P, Seyfried TN. The glucose ketone index calculator: A simple tool to mon cancer. Nutr Metab. 2015;12:12. https://doi.org/10.1186/s12986-015-0009-2
35. Van Wymelbeke V, Himaya A, Louis-Sylvestre J, et al. Influence of medium-chain and long-chain triacylglycerols on the control of food intake in men. Am J Clin Nutr. 1998;68:226-234.

36. St-Onge MP, Mayrsohn B, O'Keeffe M, et al. Impact of medium and long chain triglycerides consumption on appetite and food intake in overweight men. Eur Clin Nutr. 2014;68:1134-1140. https://doi.org/10.1038/ejcn.2014.145

37. Hill JO, Peters JC, Yang D, et al. Thermogenesis in humans during overfeeding with medium-chain triglycerides. Metabolism. 1989;38:641-648. https://doi. org/10.1016/0026-0495(89)90101-7

38. Krebs HA, Gascoyne T. The redox state of the nicotinamide-adenine dinucleotides in rat liver homogenates. Biochem J. 1968;108:513-520. https://doi.org/10.1042/ bj1080513

39. Evans M, Cogan KE, Egan B. Metabolism of ketone bodies during exercise and training: Physiological basis for exogenous supplementation. J Physiol. 2016. https://doi.org/10.1113/JP273185

40. Cox DJ, Moll ME, Gonder-Frederick LA, et al. Accuracy of time-delayed filter-paper blood glucose determination. Diabetes Care. 1988;11:517-518. https://doi. org/10.2337/diacare.11.6.517

41. Abyholm AS. Determination of glucose in dried filter paper blood spots. Scand $J$ Clin Lab Invest. 1981;41:269-274. https://doi.org/10.3109/00365518109092044

42. Winocour PH, McKinnon GA, McMurray JR, et al. Evaluation of the measurement of blood glucose levels on dried filter paper blood spots. Diabet Med. 1985;2:269-271. 